\title{
Transdermal Permeation of Trimetazidine from Nerodilol-Based HPMC Gel Drug Reservoir System across Rat Epidermis
}

\author{
Yellela S. Krishnaiah Saleh M. Al-Saidan \\ Department of Pharmaceutics, Faculty of Pharmacy, Kuwait University, Kuwait
}

\author{
Key Words \\ Trimetazidine $\cdot$ Transdermal $\cdot$ Nerodilol $\cdot$ In vitro \\ permeation $\cdot$ HPMC gel
}

\begin{abstract}
Objective: To study the in vitro transdermal permeation of trimetazidine from hydroxypropylmethyl cellulose (HPMC) gel drug reservoir system using nerodilol as a penetration enhancer. Materials and Methods: An HPMC gel containing selected concentrations of nerodilol $(0,2,4$ or $5 \% \mathrm{w} / \mathrm{v})$ and $2.5 \% \mathrm{w} / \mathrm{v}$ of trimetazidine was prepared, and subjected to in vitro permeation studies across rat epidermis. The amount of trimetazidine permeated at different time intervals (1, 2, $4,8,12,18$ and $24 \mathrm{~h}$ ) was estimated, and the data were analyzed to calculate various permeation parameters. Results: There was an increase in the amount of trimetazidine $(8,719.7$ $\pm 153.3 \mu \mathrm{g} / \mathrm{cm}^{2}$ ) permeated across the rat epidermis up to $24 \mathrm{~h}\left(\mathrm{Q}_{24}\right)$ with an increase in nerodilol concentration (5\% $w / v)$ in HPMC gel drug reservoir. However, no significant difference $(p>0.05)$ was observed in the amount of drug permeated $\left(\mathrm{Q}_{24}\right)$ with $5 \% \mathrm{w} / \mathrm{v}$ of nerodilol when compared to that obtained with $4 \% \mathrm{w} / \mathrm{v}$ of nerodilol $(8,484.5 \pm 165.8 \mu \mathrm{g} /$ $\mathrm{cm}^{2}$ ). Nerodilol, at a concentration of $4 \% \mathrm{w} / \mathrm{v}$ enhanced the flux of trimetazidine across rat epidermis by about 1.96 times when compared to control. Conclusion: The HPMC gel drug reservoir containing $4 \% \mathrm{w} / \mathrm{v}$ of nerodilol showed optimal transdermal permeation of trimetazidine.
\end{abstract}

Copyright $\odot 2007$ S. Karger AG, Basel
(C) 2007 S. Karger AG, Basel

1011-7571/08/0171-0037\$24.50/0

Fax +4161306 1234

E-Mail karger@karger.ch

www.karger.com
Accessible online at:

www.karger.com/mpp

\section{Introduction}

Transdermal therapeutic systems (TTS) provide steady-state plasma concentration of the drug for prolonged periods when applied to the skin by avoiding first pass metabolism and thereby improve bioavailability of drugs. The most important advantage of TTS is that the unwanted effects, if any, could be terminated simply by removing them from the skin. Thus, TTS are attracting the attention of healthcare professionals as these transdermal formulations have high patient compliance [1]. However, the barrier function of the skin limits the diffusion of many drug molecules, and hence several active and passive techniques are being used to enhance the transdermal drug delivery [1-3]. Transdermal drug formulations using passive techniques appear to be promising in providing a constant drug delivery as reviewed by Williams and Barry [4]. One of the passive techniques involve the use of chemical penetration enhancers which include azone and its analogues, pyrrolidones, polyunsaturated fatty acids, alkanols, polymeric enhancers, nonionic surfactants, and terpenes [4]. The safety of chemical penetration enhancers is of primary consideration while selecting them for use in the development of TTS. In this context, terpenes such as nerodilol are generally regarded as safe (GRAS) with low cutaneous irritancy, providing excellent enhancement ability and, thus appear to be promising candidates for transdermal formulations [5]. 
Trimetazidine, used in treatment of angina and hypertension, has a short half-life, and is administered 2-3 times a day with a dose ranging from 40 to $60 \mathrm{mg}$ [6]. Chronic use of conventional oral controlled release dosage forms of trimetazidine is inconvenient and may result in unwanted side effects due to high fluctuation of drug concentration in blood [1]. A well-designed membranemoderated TTS is an alternative pharmaceutical formulation that provides an effective and safe therapy with high patient compliance $[7,8]$. A $2 \% \mathrm{w} / \mathrm{v}$ of HPMC gel containing $6 \% \mathrm{w} / \mathrm{v}$ limonene (a terpene penetration enhancer) has been shown to enhance in vitro transdermal permeation of trimetazidine [8]. In the present investigation, another terpene penetration enhancer (nerodilol) was substituted for limonene in formulating HMPMC gel drug reservoir for in vitro study of transdermal permeation of trimetazidine.

\section{Materials and Methods}

\section{Materials}

Trimetazidine and nimodipine were gift samples from $\mathrm{M} / \mathrm{s}$ Dai-Ichi Karkaria Limited, Hyderabad, India, and M/s Microlabs, Bangalore, India, respectively. Nerodilol was obtained from M/s Sigma-Aldrich Laborchemikalien GmbH, Steinheim, Germany. HPMC and ethanol were obtained from M/s Sigma-Aldrich Laborchemikalien GmbH, Seelze, Germany. Acetonitrile (HPLC grade) was obtained from M/s BDH Laboratory Supplies, Poole, England. Sodium dihydrogen phosphate and o-phosphoric acid were obtained from M/s Surechem Products Ltd., Suffolk, England. Water (HPLC grade) was produced directly from Millpore filter (Millipore, Molsheim, France).

\section{Preparation of Nerodilol-Based HPMC Gel Drug Reservoir System}

HPMC powder was added to $50 \% \mathrm{v} / \mathrm{v}$ ethanol-water while being stirred at 2,500 rpm (M/s Cole-Parmer Instrument Company, Ill., USA), and the resulting mixture was mixed continuously at $37^{\circ} \mathrm{C}$ until a gel was formed. Then, trimetazidine $(2.5 \% \mathrm{w} / \mathrm{v})$ followed by nerodilol $(0,2,4$ or $5 \% \mathrm{w} / \mathrm{v})$ were added to the HPMC gel and mixed well for complete dispersion. The gel formulations were left overnight at room temperature $\left(25-28^{\circ} \mathrm{C}\right)$.

In vitro Permeation of Trimetazidine across Rat Epidermis

Modified Keshary-Chien diffusion cells were used in the in vitro permeation studies [9]. The rat epidermis, prepared as reported earlier [10], was mounted between the two compartments of the diffusion cell with the stratum corneum facing the donor compartment. High vacuum silicone grease was applied onto the donor and receptor compartments and excessive epidermal membrane at the sides was trimmed off to minimize lateral diffusion. The effective diffusional area was $6.6 \mathrm{~cm}^{2}$ and the volume of the receiver compartment was $35 \mathrm{ml}$. Two milliliters of $2 \% \mathrm{w} / \mathrm{v}$ HPMC gel drug reservoir containing the selected concentration of nerodilol $(0,2,4$ or $5 \% \mathrm{w} / \mathrm{v})$ and $2.5 \% \mathrm{w} / \mathrm{v}$ of trimetazidine was placed in the donor cell and covered with parafilm and aluminum foil to minimize evaporation of the solution. Ethanol-water $(50: 50 \mathrm{v} / \mathrm{v})$ solvent system was added to the receiver cell. The cells were maintained at $37 \pm 0.5^{\circ} \mathrm{C}$ by placing them on a magnetic stirrer with heater. The permeate samples $(0.5 \mathrm{ml})$ were withdrawn from the receiver compartments at predetermined time intervals $(1,2,4,8$, 12,18 and $24 \mathrm{~h}$ ), and an equivalent volume of drug-free vehicle $(50 \% \mathrm{v} / \mathrm{v}$ ethanol-water) was added to the receiver compartment to maintain a constant volume. The samples were assayed for trimetazidine by HPLC method. The amount of drug retained in the epidermis at the end of $24 \mathrm{~h}$ was also determined.

\section{Determination of Drug Retained in Rat Epidermis (DRE)}

At the end of the in vitro permeation study, the skin sample was removed from the cells and washed briefly in methanol (20 $\mathrm{ml}$ ) for $15 \mathrm{~s}$ to remove the adhering HPMC gel drug reservoir. Following drying at room temperature for $10 \mathrm{~min}$, the skin was cut into pieces and then homogenized in $4 \mathrm{ml}$ of methanol for $10 \mathrm{~min}$ and sonicated for $30 \mathrm{~min}$ to leach out the drug. The samples were centrifuged, the supernatant liquid filtered through a $0.45-\mu \mathrm{m}$ membrane filter, added with fixed quantity of internal standard (5 $\mu \mathrm{g} / \mathrm{ml}$ of nimodipine) and analyzed for the drug content by HPLC method.

\section{HPLC Method for the Estimation of Trimetazidine}

The quantitative estimation of trimetazidine in skin permeates, drug reservoir formulation or skin samples was estimated by HPLC method. The chromatographic system consisted of Waters 2690 automatic sample injector with a loop of $250 \mu \mathrm{l}$ and Waters 996 Photodiode Array Detector. A reversed-phase Waters Symmetry $\mathrm{C}_{18}$ column $(3.9 \times 150 \mathrm{~mm} ; 5 \mu \mathrm{m})$ and Waters Symmetry $\mathrm{C}_{18}$ guard column $(3.9 \times 20 \mathrm{~mm})$ were used. A standard curve was constructed for trimetazidine in the range of $0.2-20 \mu \mathrm{g} / \mathrm{ml}$ using nimodipine as an internal standard $(5 \mu \mathrm{g} / \mathrm{ml})$. The mobile phase used was a mixture of acetonitrile, $0.005 \mathrm{M} \mathrm{NaH}_{2} \mathrm{PO}_{4}$ and $0.02 \mathrm{KH}_{2} \mathrm{PO}_{4}$ in the ratio of $60: 5: 35$ ( $\mathrm{pH}$ adjusted to 4.0 with ophosphoric acid). The filtered mobile phase components were pumped from the respective reservoirs at a flow rate of $0.9 \mathrm{ml} /$ min. The column temperature was maintained at $40^{\circ} \mathrm{C}$. The eluent was detected at $205 \mathrm{~nm}$, and the data were acquired, stored and analyzed. Required studies were carried out to validate the HPLC method for its precision and accuracy in estimating trimetazidine in drug reservoir systems and samples of skin permeates and skin membranes. A good linear relationship was observed between the concentration of trimetazidine and the ratio of the peak area of drug to that of internal standard with a high correlation coefficient $(r=0.9999)$ in the range of $0.2-20 \mu \mathrm{g} / \mathrm{ml}$. The method was found to be precise (as shown by less than $4 \%$ of intra- and inter-day variation) and accurate as shown by $98.8 \%$ of mean recovery.

\section{Data Analysis}

The flux $\left(\mu \mathrm{g} / \mathrm{cm}^{2} \cdot \mathrm{h}\right)$ of trimetazidine was calculated from the slope of the plot of the cumulative amount of trimetazidine permeated per $\mathrm{cm}^{2}$ of skin at steady state against the time using linear regression analysis $[11,12]$. The steady state permeability coefficient $\left(\mathrm{k}_{\mathrm{p}}\right)$ of the drug was calculated by using the following equation [13]: $k_{p}=J / C$, where ' $J$ ' is the flux and ' $C$ ' is the concentration of trimetazidine in the gel. The penetration enhancing effect of nerodilol was calculated in terms of enhancement ratio (ER), and 
Table 1. Effect of nerodilol on the in vitro permeation parameters (mean $\pm \mathrm{SD}$ ) of trimetazidine from $2 \% \mathrm{w} / \mathrm{v} \mathrm{HPMC}$ gel drug reservoir across rat epidermis $(n=3)$

\begin{tabular}{|c|c|c|c|c|c|c|}
\hline $\begin{array}{l}\text { Concentration } \\
\text { of nerodilol }\end{array}$ & Flux, J, $\mu \mathrm{g} / \mathrm{cm}^{2} \cdot \mathrm{h}$ & Mean, ER & $\mathrm{Q}_{24}, \mu \mathrm{g} / \mathrm{cm}^{2}$ & Lag time, $\mathrm{h}$ & $\mathrm{k}_{\mathrm{p}}, \mathrm{cm} / \mathrm{h} \times 10^{-3}$ & DRE, $\mu g / g$ \\
\hline $0 \% \mathrm{w} / \mathrm{v}$ (control) & $194.1 \pm 7.4$ & - & $4,247.2 \pm 82.5$ & $3.0 \pm 0.3$ & $7.77 \pm 0.30$ & $1,220.1 \pm 46.9$ \\
\hline $4 \% \mathrm{w} / \mathrm{v}$ & $380.5 \pm 7.9^{*}$ & 1.96 & $8,484.5 \pm 165.8^{*}$ & $2.4 \pm 0.2$ & $15.22 \pm 0.32^{*}$ & $2,256.1 \pm 482.2^{* *}$ \\
\hline $5 \% \mathrm{w} / \mathrm{v}$ & $395.4 \pm 7.6^{*}, \#$ & 2.04 & $8,719.7 \pm 153.3^{*}, \#$ & $2.1 \pm 0.2^{* *}$ & $15.82 \pm 0.31^{*}, \#$ & $2,324.3 \pm 368.5^{* *}$ \\
\hline
\end{tabular}

${ }^{*} \mathrm{p}<0.001$ when compared to control; ${ }^{*} \mathrm{p}>0.05$ when compared to $4 \% \mathrm{w} / \mathrm{v}$ nerodilol; ${ }^{* *} \mathrm{p}<0.05$ when compared to control.

was calculated by using the following equation [14]: ER = (flux with penetration enhancer/flux without penetration enhancer) as previously described [14]. The difference in the permeation of trimetazidine with selected concentrations of nerodilol was tested for statistical significance by analysis of variance (ANOVA) with a post hoc test such as Bonferroni test for multiple comparison using SPSS $^{\odot}$ computer program (PC Version 14.0, SPSS Inc., 1989-2005).

\section{Results}

The cumulative amount of trimetazidine permeated from HPMC gel drug reservoir containing selected concentrations $(0,2,4$ and $5 \% \mathrm{w} / \mathrm{v})$ of nerodilol is shown in figure 1 . There was a steady-state permeation of the drug with a mean lag period ranging from 2.1 to $3.0 \mathrm{~h}$. The amount of trimetazidine permeated $\left(\mathrm{Q}_{24}\right)$ increased with increased concentration of nerodilol in HPMC gel drug reservoir. The value of $\mathrm{Q}_{24}$ without nerodilol (control) was $4,247.2 \pm 82.5 \mu \mathrm{g} / \mathrm{cm}^{2}$, and on adding $4 \% \mathrm{w} / \mathrm{v}$ of nerodilol it increased to $8,484.5 \pm 165.8 \mu \mathrm{g} / \mathrm{cm}^{2}$. However, there was no significant increase in the value of $\mathrm{Q}_{24}$ $\left(8,719.7 \pm 153.3 \mu \mathrm{g} / \mathrm{cm}^{2}\right)$ with $5 \% \mathrm{w} / \mathrm{v}$ of nerodilol when compared to that obtained with $4 \% \mathrm{w} / \mathrm{v}$ of nerodilol in the drug reservoir. The flux of trimetazidine was enhanced to $380.5 \pm 7.9 \mu \mathrm{g} / \mathrm{cm}^{2} \cdot \mathrm{h}$ with $4 \% \mathrm{w} / \mathrm{v}$ of nerodilol, which is about 1.96 times compared to control $\left(194.1 \pm 7.4 \mu \mathrm{g} / \mathrm{cm}^{2} \cdot \mathrm{h}\right)$. There was no significant increase ( $\mathrm{p}>0.05)$ in the flux of the drug with $5 \% \mathrm{w} / \mathrm{v}$ nerodilol $\left(395.4 \pm 7.6 \mu \mathrm{g} / \mathrm{cm}^{2} \cdot \mathrm{h}\right)$ compared to that obtained with $4 \% \mathrm{w} / \mathrm{v}$ of nerodilol $\left(380.5 \pm 7.9 \mu \mathrm{g} / \mathrm{cm}^{2} \cdot \mathrm{h}\right)$. The permeability of the drug without nerodilol was $7.77 \pm$ $0.30 \mathrm{~cm} / \mathrm{h} \times 10^{-3}$. On adding $4 \% \mathrm{w} / \mathrm{v}$ of nerodilol, there was a significant $(\mathrm{p}<0.001)$ increase in the permeability coefficient of the drug compared to control (table 1). However, there was no significant difference $(p>0.05)$

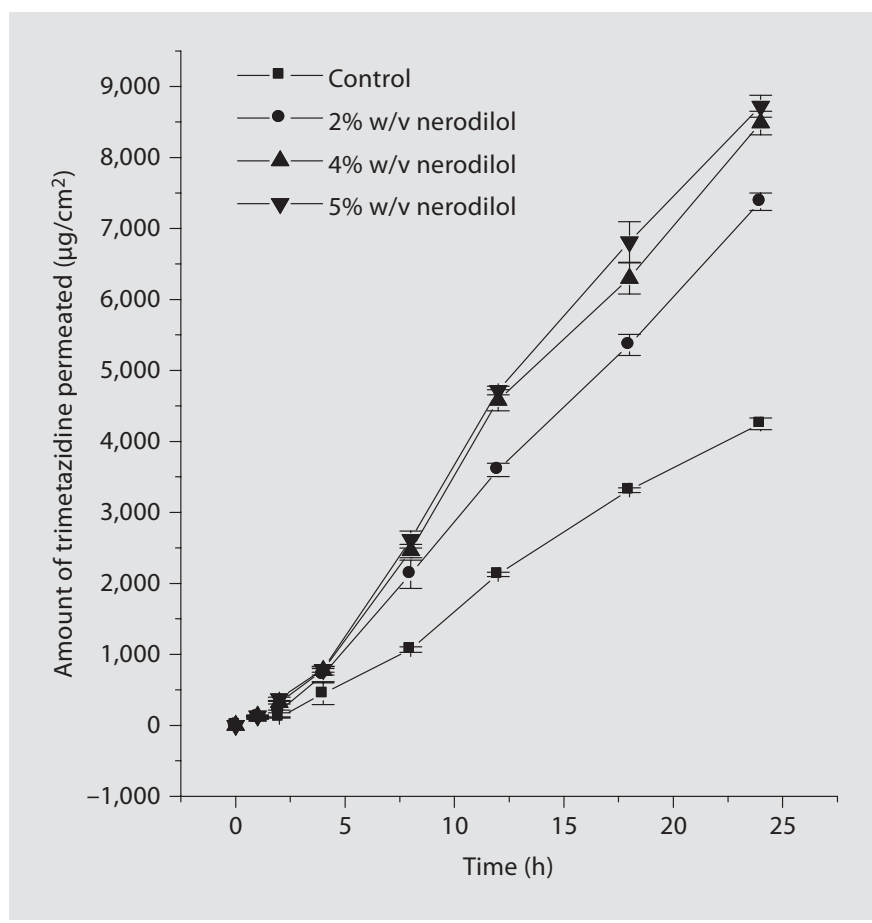

Fig. 1. Mean ( \pm SD) amount of trimetazidine permeated across rat epidermis $(n=3)$ from HPMC gel drug reservoir containing selected concentrations of nerodilol.

in the permeability coefficient of the drug with $5 \% \mathrm{w} / \mathrm{v}$ of nerodilol compared to that obtained with $4 \% \mathrm{w} / \mathrm{w}$ of nerodilol.

Without nerodilol in HPMC gel drug reservoir, the amount of drug retained in the epidermis was 1,220.1 \pm $46.9 \mu \mathrm{g} / \mathrm{g}$. The DRE increased with an increase in the concentration of nerodilol in the drug reservoir up to $2,324.3 \pm 368.5 \mu \mathrm{g} / \mathrm{g}$ with $5 \% \mathrm{w} / \mathrm{v}$. However, there was 
no significant difference $(p>0.05)$ in the value of DRE obtained with $4 \% \mathrm{w} / \mathrm{v}$ of nerodilol compared to that obtained with $5 \%$ w/v of nerodilol.

\section{Discussion}

Based on our earlier reports $[7,8], 50 \%$ v/v ethanolwater was chosen as a vehicle for formulating a terpenebased HPMC gel drug reservoir system. This is because of the ability of ethanol-water solvent system to act as penetration enhancer on its own as well as its ability to dissolve the chosen terpene enhancer (nerodilol). Ethanol permeates rapidly through human skin [15], increases the solubility of poorly soluble drugs in the donor phase [16], alters the solubility properties of skin tissue [17], changes the lipoidal pathway of stratum corneum [18] and thereby enhances transdermal drug permeation of several drugs such as estrone, $\beta$-estradiol, and hydrocortisone.

The flux of trimetazidine with $50 \% \mathrm{v} / \mathrm{v}$ of ethanol-water was $194.1 \pm 7.4 \mu \mathrm{g} / \mathrm{cm}^{2} \cdot \mathrm{h}$, whereas that reported with water in our earlier study was $52.0 \pm 0.6 \mu \mathrm{g} / \mathrm{cm}^{2} \cdot \mathrm{h}$ [7]. Thus, there was about 3.7 times increase in the flux of trimetazidine with the ethanol-water vehicle. This means that $50 \% \mathrm{v} / \mathrm{v}$ ethanol is acting as a penetration enhancer on its own. With $4 \% \mathrm{w} / \mathrm{v}$ of nerodilol, the flux of the drug increased to $380.5 \pm 7.9 \mu \mathrm{g} / \mathrm{cm}^{2} \cdot \mathrm{h}$, which is about 2 times of that obtained with the control (2\% w/v HPMC gel prepared with $50 \% \mathrm{v} / \mathrm{v}$ ethanol-water).

Although there was an apparent increase in the flux of trimetazidine with an increase in nerodilol concentration, such an increase in the flux was insignificant $(p>$ $0.05)$ with $5 \% \mathrm{w} / \mathrm{v}$ nerodilol when compared to that with $4 \% \mathrm{w} / \mathrm{v}$ nerodilol. Based on this result, $4 \% \mathrm{w} / \mathrm{v}$ of nerodilol was considered as optimal concentration for providing an optimal permeation of trimetazidine. The optimal flux $\left(380.5 \mu \mathrm{g} / \mathrm{cm}^{2} \cdot \mathrm{h}\right)$, obtained with $4 \% \mathrm{w} / \mathrm{v}$ nerodilol was about 4 times the required flux $\left(94.7 \mu \mathrm{g} / \mathrm{cm}^{2} \cdot \mathrm{h}\right)$ of trimetazidine. The required flux (J) was calculated as per the method described earlier [7, 8]. Hence, permeation study was not continued with a higher concentration $(>5 \% \mathrm{w} / \mathrm{v})$ of nerodilol. The higher flux obtained with $4 \%$ $\mathrm{w} / \mathrm{v}$ of nerodilol was necessary to account for the difference in the permeability of the rat epidermal membrane used in the present study and human skin and that of the resistance offered by the components of the transdermal patch [1].

It has been reported that terpenes increase the transdermal drug permeation mainly by disrupting the inter- cellular packing of the stratum corneum lipids [19-21]. It is then presumed that nerodilol might have disrupted the intercellular packing of the stratum corneum and thereby enhanced the permeation of trimetazidine in the present study. The findings of Fourier transform infrared studies reported earlier with nerodilol on rat stratum corneum support this hypothesis [10]. Terpenes exert their penetration enhancing activity due to their ability to permeate across the skin [21] and thereby modify the solvent nature of the stratum corneum with a resultant increase in the drug partitioning into the tissue [4]. Thus, it appears that both the $50 \% \mathrm{v} / \mathrm{v}$ ethanolwater vehicle and nerodilol (terpene) are enhancing the transdermal permeation of trimetazidine in a similar way, which resulted in an additional penetration enhancing effect. This in turn produced a higher mean enhancement ratio of about 7.3 with an ethanolic solution of $4 \% \mathrm{w} / \mathrm{v}$ nerodilol compared to that obtained with water.

The increase in the value of DRE with an increase in the concentration of nerodilol in HPMC gel drug reservoir shows that the drug retained in the skin diffused steadily. The solubility of trimetazidine has been reported to increase with an increase in the concentration of ethanol in water while optimizing the ethanol-water vehicle for designing HPMC gel drug reservoir system [7]. The enhanced flux of trimetazidine has been suggested to be due to the increased solubility of the drug in the ethanol-water vehicle [15-17]. Similarly, it is possible that nerodilol, on permeating across the skin, increased the DRE most probably by increasing the solubility of trimetazidine in the skin layers with an increase in the concentration of nerodilol in the $50 \%$ ethanol-water vehicle from $457.5 \pm 2.7$ to $876.9 \pm 11.9 \mathrm{mg} / \mathrm{ml}$ in 0 and $5 \%$ w/v nerodilol, respectively. This indicates that nerodilol, after permeating through the skin, enhanced the DRE levels in the skin and thereby increased the transdermal flux of trimetazidine $[4,21]$. It is possible that trimetazidine diffused at a steady state due to the increased quantity of drug retained in the skin such that the skin was controlling the release of trimetazidine. However, in an ideal TTS, the device is expected to control the drug release across the skin. In the present study it appeared that the skin was controlling drug release from the nerodilolbased HPMC gel drug reservoir system instead of the transdermal drug delivery system.

The lag period for producing steady state permeation of the drug across the rat epidermis decreased with an increase in nerodilol (table 1). However, the decrease in the lag period was significant $(\mathrm{p}<0.05)$ only with $5 \%$ 
$\mathrm{w} / \mathrm{v}$ of nerodilol in the drug reservoir. This indicates that nerodilol is interacting with the skin more or less at the same rate as an increase in the nerodilol concentration. However, there was a significant increase in the extent of nerodilol-skin interaction as evidenced by the increase in the flux of trimetazidine. Terpenes act as penetration enhancers due to their ability to modify the solvent nature of the stratum corneum and thereby improve drug partitioning into the tissue [4]. Mostly for this reason, the quantity of drug retained in the skin membrane (DRE) at the end of in vitro permeation study increased, with an increase in the concentration of nerodilol in the HPMC drug reservoir (table 1). Many terpenes permeate human skin well [21], which in turn increase the thermodynamic activity of the drug in the formulation. Small angle Xray diffraction studies indicated that nerodilol reinforces the bilayers, possibly by orientating alongside the stratum corneum lipids [22]. Nerodilol is a saturated secondary alcohol (lipophilicity as denoted by $\log \mathrm{P}$ is 5.36 ) and, the highly lipophilic nerodilol might have produced a high penetration enhancing activity of weakly lipophilic trimetazidine (log $\mathrm{P}=0.60)$ across the skin membrane [23].

Our earlier reports $[10,24]$ showed that nerodilol at a concentration of $10 \% \mathrm{w} / \mathrm{w}$ enhanced the transdermal permeation of nicorandil in human volunteers with no signs of damage or irritation when nerodilol-based patch was applied to the skin. This indicates that the optimal concentration of nerodilol $(4 \% \mathrm{w} / \mathrm{v})$ is unlikely to cause any damage to the stratum corneum on application of the transdermal patch to humans. Though nerodilol showed enhanced permeation, the transdermal components of the proposed membrane-moderated TTS, such as ratecontrolling membrane (e.g. EVA2825) and adhesive coat, may exhibit their own resistance to the permeation of trimetazidine across them. This has to be taken into account before fabricating the proposed membrane-moderated TTS of trimetazidine. Such studies were carried out and reported separately.

\section{Conclusion}

The results of the in vitro permeation studies across the rat epidermis showed that HPMC gel drug containing $4 \% \mathrm{w} / \mathrm{v}$ of nerodilol provided optimal transdermal permeation of trimetazidine.

\section{Acknowledgements}

This research work was supported by Kuwait University Research Grant No. PP01/04.

\section{References}

1 Barry BW: Novel mechanisms and devices to enable successful transdermal drug delivery. Eur J Pharm Sci 2001;14:101-114.

$\checkmark 2$ Tao SL, Desai TA: Microfabricated drug delivery systems: from particles to pores. Adv Drug Deliv Rev 2003;55:315-328.

$>3$ Cross SE, Roberts MS: Physical enhancement of transdermal drug application: is delivery technology keeping up with pharmaceutical development? Curr Drug Deliv 2004;1:81-92.

$\checkmark 4$ Williams AC, Barry BW: Penetration enhancers. Adv Drug Deliv Rev 2004;56:603618.

-5 Gao S, Singh J: In vitro percutaneous absorption enhancement of lipophilic drug tamoxifen by terpenes. J Control Release 1998;51: 193-199.

-6 McClellan KJ, Plosker GL: Trimetazidine: a review of its use in stable angina pectoris and other coronary conditions. Drugs 1999;58: 143-157.
7 Krishnaiah YSR, Al-Saidan SM: Development of ethanol-water co-solvent system for an optimal transdermal permeation of trimetazidine. Controlled Release Society 32nd Annual Meeting and Exposition Transactions, 2005, p 178.

8 Krishnaiah YSR, Al-Saidan SM: In vitro permeation of trimetazidine from limonenebased HPMC gel drug reservoir across rat epidermis. Proc 2nd EUFEPS Conf Optimising Drug Delivery and Formulation: Evaluation of Drug Delivery Systems, Issues and Perspectives, 2005, vol 45, pp 113-114.

$\checkmark 9$ Keshary PR, Chien YW: Mechanism of transdermal controlled nitroglycerin administration. 2. Assessment of rate controlling steps. Drug Dev Ind Pharm 1984;10: 1663-1699.

10 Krishnaiah YSR, Al-Saidan SM, Chandrasekhar DV, Rama B: Effect of nerodilol and carvone on in vitro permeation of nicorandil across rat epidermal membrane. Drug Dev Ind Pharm 2006;32:423-435.
11 Ho HO, Chen LC, Lin HM, Sheu MT: Penetration enhancement by menthol combined with a solubilization effect in a mixed solvent system. J Control Release 1998;51:301-311.

12 Yamane MA, Williams AC, Barry BW: Terpene penetration enhancers in propylene glycol/water co-solvent systems: effectiveness and mechanism of action. J Pharm Pharmacol 1995;47:978-989.

13 Williams AC, Barry BW: Terpenes and the lipid-protein-partitioning theory of skin penetration enhancement. Pharm Res 1991: 8:17-24.

14 Konsil J, Parrott KA, Ayres JW: Development of a transdermal delivery device for melatonin in vitro studies. Drug Dev Ind Pharm 1995;21:1377-1387.

15 Berner B, Otte JH, Mazzenga GC, Steffens RJ, Ebert CD: Ethanol:water mutually enhanced transdermal therapeutic system. 1. Nitroglycerin solution properties and membrane transport. J Pharm Sci 1989;78:314318 . 
16 Pershing LK, Lambert LD, Knutson K: Mechanism of ethanol-enhanced estradiol permeation across human skin in vivo. Pharm Res 1990;7:170-175.

-17 Megrab NA, Williams AC, Barry BW: Estradiol permeation across human skin, silastic and snake skin membranes: effects of ethanol/water co-solvent systems. Int J Pharm 1995;116:101-112.

18 Ghanem AH, Mahmoud H, Higuchi WI, Liu P, Good WR: The effects of ethanol on the transport of lipophilic and polar permeants across hairless mouse skin: methods/validation of a novel approach. Int J Pharm 1992; 78:137-156.
19 Cornwell PA, Barry BW, Stoddart CP, Bouwstra JA: Wide-angle X-ray diffraction of human stratum corneum: effects of hydration and terpene enhancer treatment. J Pharm Pharmacol 1994;46:938-950.

20 Zhao K, Singh J: Mechanisms of percutaneous absorption of tamoxifen by terpenes: eugenol, D-limonene and menthone. J Control Release 1998;55:253-260.

21 Williams AC, Barry BW: Terpenes and the lipid-protein-partitioning theory of skin penetration enhancement. Pharm Res 1991; $8: 17-24$.
22 Cornwell PA, Barry BW, Bouwstra JA, Gooris GS: Modes of action of terpene penetration enhancers in human skin; differential scanning calorimetry, small-angle X-ray diffraction and enhancer uptake studies. Int J Pharm 1996;127:9-26.

23 Mofat AC, Osselton MD, Widdop B: Clarke's Analysis of Drugs and Poisons in Pharmaceuticals, Body Fluids and Postmortem Material. London, Pharmaceutical Press, 2004.

24 Krishnaiah YSR, Al-Saidan SM, Chandrasekhar DV, Satyanarayana V: Bioavailability of nerodilol-based transdermal therapeutic system of nicorandil in human volunteers. J Control Release 2005;106:111122. 